\title{
Fear of missing out and self-esteem as mediators of the relationship between maximization and problematic smartphone use
}

\author{
Rocco Servidio ${ }^{1}$ (DD \\ Accepted: 30 December 2020 / Published online: 2 February 2021 \\ (C) The Author(s) 2021
}

\begin{abstract}
Problematic smartphone use (PSU), which involves an excessive and uncontrolled use of smartphones, thereby causing daily-life disturbance, has been associated with a range of negative outcomes including anxiety, depression, and deficits in social relationships. However, the relationship between PSU and maximization, which could be an explanatory factor, has not yet been thoroughly studied. Drawing on the Interaction-Person-Affect-Cognition-Execution (I-PACE) model, the current study aimed to investigate the association between PSU and maximization with the assumption that fear of missing out (FoMO) and selfesteem could mediate this relationship. Empirical data were gathered from 277 Italian university students who completed an online survey. Correlation analysis and structural equation modelling (SEM) were used to investigate the relationships among the variables. The results showed that PSU, maximization, and FoMO were positively correlated; whereas maximization and selfesteem were negatively correlated. Furthermore, FoMO and self-esteem partially mediated that relationship, suggesting that participant maximizers experience more FoMO, especially when the participants have fear of missing out on potentially "better" alternatives to social experiences and exhibit low self-esteem. Thus, higher FoMO and low self-esteem can be a driver of PSU. Finally, this study provides new insights about how maximization may have an impact on the development of addictive behaviour such as PSU.
\end{abstract}

Keywords Problematic smartphone use $\cdot$ Maximization $\cdot$ Self-esteem $\cdot$ FoMO $\cdot$ I-PACE

\section{Introduction}

The rapid diffusion and adoption of smartphones, tablets and smartwatches, have greatly facilitated people's access to goods and services found on the web. This ease of access, however, has translated into increased hours of connectivity such that the amount of time people spend on their smartphones has become a growing concern, prompting several scholars to explore whether their excessive use could lead to addictive behaviours (Duke \& Montag, 2017; Kim et al., 2016; Lo Coco et al., 2020; Servidio, 2019). The addictive use of the Internet is often denominated by such terms as: social media addiction, Facebook addiction, and problematic

Rocco Servidio

servidio@unical.it

1 Department of Cultures, Education and Society, University of Calabria, Via Pietro Bucci, Building Cube 20/B, 87036 Arcavacata di Rende, Cosenza, Italy smartphone addiction (Choi et al., 2014; Marino, Gini, Vieno, \& Spada, 2018), among others. While Internet addiction and problematic smartphone addiction are two different terms, they are closely related and refer to the overuse of online communication technologies characterised by constant interaction with others (Wegmann \& Brand, 2016).

Problematic Smartphone Use (PSU) is a recent construct which is described as the excessive use of the smartphone, accompanied by addiction-like behaviour such as withdrawal (when unable to use one's phone) and tolerance (increased use to obtain the same level of satisfaction) (Elhai, Levine, \& Hall, 2019; Rozgonjuk \& Elhai, 2019). Indeed, PSU can involve deficits in social relationships, work and/or school performance, and can even lead to family disputes caused by excessive smartphone use because of too many hours spent on social media interaction (Billieux, Maurage, LopezFernandez, Kuss, \& Griffiths, 2015). Additionally, results from several previous studies found an association between PSU and poor mental health condition including depression and anxiety (Coyne, Stockdale, \& Summers, 2019; Kara, 
Baytemir, \& Inceman-Kara, 2019), sleep deficits (Zhang \& Wu, 2020), low self-esteem (Lannoy et al., 2020), low selfcontrol (Servidio, 2019), and lower motivation in doing physical activities (Pereira, Bevilacqua, Coimbra, \& Andrade, 2020). We should underline, however, that PSU is not actually included in the official diagnosis of the International Classification of Diseases (ICD-11) or the Diagnostic and Statistical Manual of Mental Disorders (DSM-5) and does not seem to pose the same risks that drug and alcohol use disorders do. However, Montag, Wegmann, Sariyska, Demetrovics, and Brand (2019) indicate that PSU falls into the realm of mobile Internet use disorders. Thus, based on preliminary evidence, we believe that studying PSU may be useful in complementing what we know of the effects of technological addictive disorders and allows us to better specify which variables potentially drive PSU.

A relevant theory that helps us understand the addictive use of Internet applications relating to gambling, gaming, and pornography use, among others, is the Interaction of PersonAffect-Cognitive-Execution model (I-PACE) (Brand et al., 2019; Brand, Young, Laier, Wölfling, \& Potenza, 2016). Since the I-PACE conceptualization has further been extended to include research on PSU disorders (Oberst, Wegmann, Stodt, Brand, \& Chamarro, 2017; Rozgonjuk \& Elhai, 2019; Servidio, 2019), its theoretical framework was deemed appropriate for this study. The framework emphasizes the interaction among a person's core characteristics and the cognitive, affective, and executive processes as it attempts to explain the mechanisms underlying the development and maintenance of a specific Internet-use disorder such as PSU. It also illustrates the different levels of the addiction process in disorders that include, but are not limited to Internet-gaming. It poses that the development of problematic and addictive behaviour occurs when there is an interaction between an individual's predisposing variables (e.g., depression, anxiety, and personal factors) and certain aspects related to specific situations (Brand et al., 2016; Brand et al., 2019). The result of the interaction is an experience of gratification and compensation associated with specific Internet-related behaviour (e.g., paying attention to specific stimuli, or feeling the desire to play online). On the other hand, the affective and cognitive response variables are conceptualized as influencing the choice of Internet technology, which can result in adaptive or dysfunctional behaviour.

A person, for example, could use his or her own smartphone to alleviate the burden of real-life problems, to avoid loneliness, or to experience pleasure and positive emotions from the simple fact that one is online (Brand et al., 2016). These expectancies can influence not only the individual's behaviour, but also the decision to use or not use a specific Internet and/or smartphone application (Wegmann $\&$ Brand, 2016). Thus, certain motives and predisposing factors are reinforced by the effects of the gratification experienced and the escape from negative emotions. Consequently, this may lead to excessive use of the preferred Internet and/or smartphone application, resulting in reduced control and stabilization of the person's core characteristics.

Thus, within the conceptualization of I-PACE, this study focuses on the following variables: first, maximization as a personality trait that represents the general tendency to strive for the best possible option, and leads to delayed decisions (Schwartz et al., 2002); second, a state variable such as fear of missing out (FoMO), which is the apprehension of missing out on rewarding experiences, leading to a corresponding need to stay persistently connected with one's social network (Przybylski, Murayama, DeHaan, \& Gladwell, 2013); and third, self-esteem, which is another personality variable potentially involved in the risk of PSU (Lannoy et al., 2020). The proposed relationships are analysed through correlational analysis and the Structural Equation Modelling (SEM) to test the mediating effects. Finally, because the role of individual characteristics (e.g., age and gender) in the risk of PSU is often inconsistent (Chen et al., 2017), all these variables were included as covariates.

\section{Maximization as a Possible Predictor of PSU}

Maximization may be one among several characteristics of an individual that is linked to smartphone overuse. It has been conceptualized as a personality trait which describes individual differences in the general tendency of striving to make the best choice (for reviews see, Misuraca \& Fasolo, 2018; Cheek \& Schwartz, 2016). According to Schwartz et al. (2002), maximization is an inclination to look for the best alternative possible through systematic and exhaustive searches. The construct of maximization has been widely applied in exploring decisionmaking strategies regarding consumer behaviour experiences.

Findings based on the construct of maximization have revealed that people who display tendencies to maximize have less life-satisfaction, happiness, optimism, and self-esteem (Newman, Schug, Yuki, Yamada, \& Nezlek, 2018); they are also depressed, anxious, and impulsive (Purvis, Howell, \& Iyer, 2011; Schwartz et al., 2002). It has also been shown that maximizers tend to report maladaptive decision-making strategies, avoid making decisions (Schwartz et al., 2002), exhibit less behavioural coping strategies and show greater tendency to depend on others for their decisions (Parker, de Bruin, \& Fischhoff, 2007). Another set of studies has revealed that maximizers are more prone to social comparison (Polman, 2010) and are unhappy when they discover that others selected better choices compared to theirs, even if their own choice was better than expected (Huang \& Zeelenberg, 2012).

Although maximization has not been extensively investigated in the field of PSU, there is a recent study that has linked maximization to problematic social network use. Specifically, this study found that tendencies to maximize and to 
procrastinate lead to problematic social networks use, especially in cases when there is a high incidence of specific fears and intentions to discover, or to avoid missing out on a potentially "better" alternative for social experiences (Müller, Wegmann, Stolze, \& Brand, 2020). Moreover, another study shows that specific online addictions such as PSU, social media addiction, and Internet gaming disorder share the same features with generalized Internet addiction (Chen et al., 2020). It has also been suggested that PSU is associated with social media addiction because persons tend to use their smartphone as easy and portable access to social media applications (Kuss et al., 2018; Sha, Sariyska, Riedl, Lachmann, \& Montag, 2019).

People with the tendency to maximize and who receive social media notifications on their smartphone and/or smartwatch about social events could be more susceptible to experiencing negative feelings because of the need to maximize the many choices and decisions they would have to make to avoid missing out on new social experiences. According to the I-PACE model (Brand et al., 2016; Brand et al., 2019), this subjective stress response to situational factors may influence the decision to use Internet-related technologies, such as the smartphone, to cope with the associated cognitions and affects. Therefore, people who think that they can solve specific problems by going online could be led to an uncontrolled and impulsive use of online communication applications. Indeed, similar to those with Internet-addictive behaviour, maximizers tend to delay decision-making but exhibit impulsivity in making such decisions in favour of options that offer immediate gratification (Müller et al., 2020). The negative impact of this impulsivity on PSU has been documented since previous studies have provided evidence of impulsivity as a risk factor for PSU (Kim et al., 2016; Servidio, 2019). In fact, Billieux et al. (2015) proposed a theoretical framework in which PSU is driven by impulsivity leading to excessive smartphone use.

No previous studies have examined the link between maximization and PSU, even if the study by Müller et al. (2020) has investigated the relationship between maximization and problematic social network use. Overall, considering the existing studies, we can make a reasonable hypothesis that tendencies towards maximization could be related to PSU (H1). This hypothesis is in line with the assumption taken by the I-PACE model, which illustrates how personality factors and social situations could lead to high expectancies, and in this case, smartphone-use could represent a dysfunctional coping strategy of escaping from negative feelings and of experiencing pleasure by going online to maximize personal needs.

\section{The Mediating Role of FoMo and Self-Esteem}

Given the scarcity of studies examining the potential influence of maximization on PSU, little is known regarding the mediating mechanisms underlying this relationship. Thus, the current study was interested in exploring whether fear of missing out (FoMO; Przybylski et al., 2013) and self-esteem could mediate the relationship between maximization and PSU.

In recent years, FoMO has received great attention since most of the existing researches focus on the question of whether FoMO is connected to an increased use of social media (e.g., Alt \& Boniel-Nissim, 2018; Milyavskaya, Saffran, Hope, \& Koestner, 2018). The proliferation of social media applications and the related rise in smartphone use have heightened people's awareness of possibly missing out on potentially exciting social experiences. In this vein, an assumption could be made that the frequent reception of notifications on smartphones and/or smartwatches, reminding people of potentially more rewarding alternatives, could increase feelings of FoMO (Milyavskaya et al., 2018; Müller et al., 2020). Furthermore, it is likewise well known that people who score high in FoMO are likely to overuse their smartphones to satisfy the desire of staying connected (Rozgonjuk, Sindermann, Elhai, \& Montag, 2020).

Similar to maximization, a high score in FoMO has been found to show higher levels of regret indicating that FoMO plays an important role in the context of PSU and social media addiction (Oberst et al., 2017; Wegmann, Oberst, Stodt, \& Brand, 2017). Moreover, current studies show that FoMO is associated to alcohol consumption (Riordan, Flett, Cody, Conner, \& Scarf, 2019), and lower levels of life satisfaction (Casale, Rugai, \& Fioravanti, 2018). Additionally, other researchers have demonstrated that FoMO is associated with PSU and other online addictive behaviours, such as excessive social media use (Elhai et al., 2018).

Recently, Milyavskaya et al. (2018) drew further similarities between FoMO and maximization. Specifically, starting from the assumption that having too many choices can lead to choice paralysis, "FoMO can be thought to arise from an abundance of choices among activities or experiences, particularly those of a social nature, coupled with an uncertainty over the 'best' choice and anticipatory regret over the options not selected" (Milyavskaya et al., 2018, p. 725). Thus, people who score higher in maximization might have increased feelings of FoMO. Accordingly, this study hypothesizes that tendencies towards maximization predict the severity of the experience of FoMO (H2).

Additionally, empirical studies have examined the mediating role of FoMO in the relationship between psychological variables and PSU. For example, Wang et al. (2019a) found that procrastination and FoMO partially mediated the relationship between sensation seeking and smartphone addiction. Another study indicated that envy was positively related to PSU, with FoMO mediating this relationship (Wang et al., 2019b). Moreover, another study shows that people who score high in FoMO are more prone to check the notifications on 
their smartphone, as well as to update their social media profile and status because they want to be part of the online community, which behaviour may result in developing the risk of PSU (Long, Wang, Liu, \& Lei, 2019). Consequently, they may develop an addictive PSU behaviour due to an almost compulsive use of such communication tools.

Following these lines of research, the present study hypothesizes that FoMO could mediate the relationship between maximization and PSU (H3). The reception of frequent reminders of alternatives, and the thought of possibly missing out on social experiences which are perhaps more gratifying, could be positively associated with PSU (Milyavskaya et al., 2018; Müller et al., 2020). In the I-PACE model, FoMO is a cognitive or affective response driven by predisposing variables such as personality traits, and which in turn contribute to PSU (Brand et al., 2016).

With regard to self-esteem, although prior scholars have investigated the relationships between personality traits and PSU, few studies have explored its role in PSU (Lannoy et al., 2020). According to Rosenberg (1965), self-esteem is one's positive or negative attitude toward oneself and one's evaluation of one's own thoughts and feelings overall in relation to oneself. People with high self-esteem tend to use technologies in a balanced manner, tend to positively cope with stressful situations, and develop a positive attitude towards life (Servidio, Gentile, \& Boca, 2018). On the other hand, people with low self-esteem try to find shelter in the Internet network, which allows them to control the selfaspects they want to make public. Similar to what is commonly observed with other forms of addictive behaviour, low self-esteem is associated with Internet addiction and with the compulsive use of social media applications (Andreassen, Pallesen, \& Griffiths, 2017).

A cross-sectional study showed that dysfunctional attitudes and self-esteem were found to be mediators between anxious attachment styles and smartphone addiction (Yuchang, Cuicui, Junxiu, \& Junyi, 2017). Another study found that self-esteem mediated the link between adolescent studentstudent relationship and PSU (Wang et al., 2017). Moreover, the results of a recent meta-analysis identified that self-esteem, among other psychopathological variables, was inconsistently related to PSU, with small to medium effects (Elhai, Dvorak, Levine, \& Hall, 2017). Overall, these results suggest exploring the role of self-esteem by including new constructs.

As regards the relationship between maximization and selfesteem, one study shows that people with high maximization tendencies, compared to satisfiers, are more sensitive to experiencing low self-esteem (Misuraca \& Fasolo, 2018). The behaviour of maximizers is characterized by a high need for scrupulousness and order that reduces self-esteem and optimism and increases high levels of regret, because they sacrifice limited resources in an attempt to discover the best options (Newman et al., 2018). In relation to smartphone use, people tend to use their own smartphone to search for the best alternative, and in turn reinforce the decision to remain connected online, thus increasing the risk of developing addictive behaviours.

To date, however, few studies have examined the mediating role of self-esteem in the relation between personality traits and PSU. Based on the literature reviewed above, this study hypothesizes that maximization is negatively associated with self-esteem, which in turn is negatively associated with PSU (H4). In other words, self-esteem mediates the relationship between maximization and PSU (H5).

\section{The Present Study}

Taking all the previous discussions together, it is assumed that an individual with the tendency to maximize would most likely have the propensity for PSU. This association between maximization and PSU could be mediated by specific variables related to opinions and feelings of potentially missing out on significant events that occur online (e.g., FoMO), and by a miximizer's low levels of self-esteem, which in turn could increase PSU. Thus, the tendency to avoid missing out on potentially better social experiences may reinforce a dysfunctional and uncontrolled use of the smartphone, resulting in higher symptoms of PSU. These cyclic relationships are consistent with the assumption taken by the I-PACE model, given that previous gratification experiences in the use of Internet-based applications tend to change the subjective reward expectations that are associated with the specific behaviour.

Finally, even though much is known about the association between personality traits and PSU, no previous studies have investigated the effects of other personality traits, like maximization, on this relationship, and how FoMO and self-esteem may affect the link between maximization and PSU. Investigating these relationships may give new insights by providing additional knowledge to PSU studies, as maximization could be a predisposing variable that leads to PSU. Additionally, including FoMO and self-esteem into this relationship may explain their mechanisms in the association.

\section{Method}

\section{Participants}

A sample of 277 undergraduate students was recruited from an Italian public university during the 2019-2020 academic year. The sample consisted of 68 males $(24.5 \%)$ and $207 \mathrm{fe}-$ males $(74.7 \%)$. Two students did not report their gender $(0.7 \%)$. The participants' ages ranged from 19 to 38 ( $M=$ 23.46, $S D=3.56)$. Most participants attended psychological and educational courses $(64.6 \%)$; the rest were enrolled in various courses such as economics $(4 \%)$, healthcare $(5.8 \%)$ 
and a scientific one (13.7\%). The remaining students (11.9\%) did not indicate their degree courses.

\section{Measures}

\section{Maximization Scale}

The Maximization scale (Schwartz et al., 2002) was used to measure the individual maximizing tendency. The scale was translated from English to Italian according to the recommendations of the International Test Commission (2017). It contains 13 items (e.g., I often find it difficult to shop for a gift for a friend) and the participants reported the extent to which each statement described them, using a seven-point Likert scale ranging (from 1 = "strongly disagree" to $7=$ "strongly agree") with higher scores indicating higher maximization tendencies. The scale revealed a satisfactory internal reliability, $\alpha=.75$ $(M=3.78, S D=.97)$. Finally, confirmatory factor analysis showed that all the items loaded on the scale, indicating that the construct validity of the instrument was good, $\chi^{2}$ S-B $(60, N=270)=85.82, p=.018, \mathrm{CFI}=.941, \mathrm{TLI}=.923$, RMSEA $=.040,90 \%$ CI $[.02, .06]$, SRMR $=.050$.

\section{Fear of Missing out Scale}

The Italian version of the Fear of Missing Out (FoMO) scale was used to measure the adolescents' disposition towards fear of missing out (Casale \& Fioravanti, 2020; Przybylski et al., 2013). The scale comprises 10 items (e.g., I fear others have more rewarding experiences than me), measured on a fivepoint Likert type (from $1=$ "not at all true of me" to $5=$ "extremely true of me"). For the present study, the reliability of the scale was, $\alpha=.70$.

\section{Rosenberg Self-Esteem Scale}

The Italian version of the Rosenberg Self-Esteem scale (Prezza, Trombaccia, \& Armento, 1997) was used to measure the subjective feelings of self-value and self-acceptance. Participants rated their agreement with 10 statements (e.g., "I feel that I have a number of good qualities") on a four-point Likert type (from $1=$ "strongly agree" to $4=$ "strongly disagree"). Higher scores indicate higher self-esteem. The internal consistency in the sample of this present study, $\alpha=.86$, was good.

\section{Problematic Smartphone Use Scale}

The short Italian version of the 10 items-Problematic Smartphone Use scale for adolescents and young adults was used (PSU; De Pasquale, Sciacca, \& Hichy, 2017; Kwon, Kim, Cho, \& Yang, 2013). Participants gave their answer on a six-point Likert scale (from $1=$ "strongly disagree" to $6=$ "strongly agree") with higher scores indicating higher PSU. A sample item is "I have used my Smartphone longer than I had intended". The PSU scale showed good reliability and validity for the assessment of PSU and the Italian version has shown good psychometric properties as well (see also, Servidio, 2019). The scale reliability in the current sample was, $\alpha=.82$.

\section{Procedure}

A cross-section web-based survey was conducted, which provided a battery of assessment aimed at investigating individual behaviour towards digital technologies. Additionally, the participants were asked to provide demographic information about their gender, age, and degree course. A snowball procedure was applied in recruiting the participants. Specifically, it consisted of having a participant ask colleagues or fellow university students to complete the survey, and those new participants, in turn, recruited other university students they knew and so on. The information about the study was emailed with the link of the survey to undergraduate students. Furthermore, the link of the survey was posted on a Facebook wall. Only measures relevant to the current research are reported.

All participants were informed of the study's objectives and were guaranteed strict confidentiality in their answers to the questionnaire. Those who agreed to participate in this study signed an online informed consent form, and were invited to complete an anonymous questionnaire. All participants volunteered for the study and none of them received any kind of remuneration. Moreover, they were also given the opportunity to withdraw the data from the study at any stage. Completing the online survey took approximately $25 \mathrm{~min}$.

\section{Statistical Analyses}

Before performing the data analyses, all the variables were screened for linearity, homoscedasticity, and homogeneity of variance. Additionally, univariate normality (skewness and kurtosis), multivariate outliers, and cases with missing values were checked. The scatterplot of standardised predicted values versus standardised residuals, showed that the data met the assumptions of linearity and the residuals were approximately normally distributed. This suggests that the data does not violate the assumption of homoscedasticity. The Levene's $F$ test revealed that the homogeneity of variance assumption was met with, $p=.166$. Following the general recommendations for skewness and kurtosis, our variables were normally distributed (Tabachnick \& Fidell, 2014); the highest skewness value was, .73 (FoMO), and for kurtosis was, -.41 (Maximization). By computing the Mahalanobis distance with, $p<.001$ for the chi-square $\left(\chi^{2}\right)$ distribution value (Tabachnick \& Fidell, 2014), no multivariate outliers among the cases were identified. No cases had missing data. Descriptive statistics and Pearson's correlation analyses were 
computed. The internal reliability was obtained by computing the alpha of Cronbach $(\alpha)$. SPSS 25 package was used to run the preliminary statistical procedures.

A partial and a full mediating model were separately tested to verify whether the proposed mediators, self-esteem, and FoMO fully explained the relationships between maximization and PSU. Age and gender were also controlled. Confirmatory factor analysis (CFA) and structural equation modelling (SEM) were performed using Mplus 7.04 (Muthén \& Muthén, 2014). As Hu and Bentler (1999) recommended, multiple indices were used to evaluate the model fit (adopted cut-offs in brackets): the chisquare $\left(\chi^{2}\right)$ test value with the associated $p$ value $(p>.05)$, comparative fit index (CFI $\geq .95)$, Tucker-Lewis Index (TLI $\geq .95)$, root-mean-squared error of approximation (RMSEA $\leq .06)$, and its $90 \%$ confidence interval, and standardized root mean square residual (SRMR < .08). Both confirmatory and SEM were estimated with the maximum-likelihood parameter with standard errors and a mean-adjusted chi-square test statistic that were robust to non-normality (MLM) as Maydeu-Olivares (2017) suggested. The MLM chi-square test statistic is also referred to as the Satorra-Bentler (S-B) chi-square.

With regard to the SEM, item parcelling was applied (Little, Cunningham, Shahar, \& Widaman, 2002) to define each construct of the model on a latent level. The item parcelling was built by applying a balanced method, which aims to combine high and low inter-correlations values (Little, Rhemtulla, Gibson, \& Schoemann, 2013). Finally, the partial mediating model and the full mediating model were compared to determine the mediating role of self-esteem and FoMO in the relationship between maximization and PSU. The models were evaluated by using a chi-square $\left(\chi^{2}\right)$ difference test, which provides a statistical test of whether the constraints are justified (Kline, 2016). To establish significant differences between models, at least two out of three criteria had to be satisfied: $\Delta \chi^{2}$ significant at, $p<.05, \Delta \mathrm{CFI} \leq .005$, and $\Delta$ RMSEA $\leq .010$ (Chen, 2007).

\section{Ethics}

All the research materials and procedures were designed and conducted according to the ethical standards laid out by the Italian Psychological Association (AIP) and the Declaration of Helsinki.

\section{Results}

\section{Descriptive and Correlations}

Means, standard deviations, and bivariate correlations of the measurements of maximization, self-esteem, FoMO, PSU, age, and gender are shown in Table 1. The mean of maximization score indicates tendencies towards maximizers rather than satisfiers (who are inclined to attempt to find a tree that works for them rather than the best one) in the current sample. Finally, all the correlations between the constructs are significant and satisfy the conditions for performing the SEM analysis.

\section{Structural Equation Modelling and Mediation Analysis}

Figure 1 illustrates the findings from the SEM used to analyse the hypotheses of the present study and includes the standardized estimates. The hypothesized model provided a good fit to the data, $\chi_{\text {S-B }}^{2}(59, N=275)=90.22, p=.005, \mathrm{CFI}=.966$, TLI $=.955$, RMSEA $=.044,90 \%$ CI $[.02, .06]$, $\mathrm{SRMR}=.061$. Age and gender were predictors of PSU. Finally, PSU accounted for $35 \%$ of the variance.

Table 2 shows the results of the mediation analysis and the indirect effects for PSU and its predictor and mediators' variables.

The results of the analysis indicated that the relationship between maximization and PSU was partially mediated by self-esteem and FoMO. As for the indirect effects, both selfesteem and FoMO indirectly affected the association between maximization and PSU.

Next, a full mediated model and a partially mediated one were tested. Although the full mediated model provided sufficient fit to the data, $\chi^{2}{ }_{\text {S-B }}(60, N=275)=113.96, p=.000$, $\mathrm{CFI}=.941, \mathrm{TLI}=.924, \mathrm{RMSEA}=.060,90 \%$ CI $[.04, .07]$, $\mathrm{SRMR}=.072$, after comparing the two models, the results showed that the full mediated model fits the data worse, $\Delta \chi^{2}(1)=26.27, p<.001, \Delta \mathrm{CFI}=-.025, \Delta \mathrm{RMSEA}=.013$. Therefore, the less restricted model fits the data better than the smaller model in which some parameters are fixed. Thus, the partial mediating model was selected as the final one.

\section{Discussion}

The aim of the current study was to investigate the predictive role of maximization on PSU, and the mediating effects of FoMO and self-esteem in this relationship.

Table 1 Descriptive statistics and correlations between the measures of maximization, self-esteem, FoMO, PSU, age, and gender

\begin{tabular}{lcrllllll}
\hline & $M$ & $S D$ & 1 & 2 & 3 & 4 & 5 & 6 \\
\hline 1. Maximization & 49.17 & 12.58 & - & & & & \\
2. Self-Esteem & 29.68 & 4.84 & $-.19^{* * * *}$ & & & & \\
3. FoMO & 19.60 & 5.23 & $.31^{* * * *}$ & $-.13^{*}$ & & & & \\
4. PSU & 27.00 & 9.33 & $.47^{* * *}$ & $-.21^{* * *}$ & $.31^{* * *}$ & - & \\
5. Age & 23.46 & 3.56 & -.09 & .08 & $-.11^{*}$ & .07 & - \\
6. Gender $^{\mathrm{a}}$ & - & - & .03 & $-.12^{*}$ & -.00 & $.12^{*}$ & -.10 & - \\
\hline
\end{tabular}

Note. FoMO $=$ Fear of Missing Out. PSU = Problematic Smartphone Use

${ }^{\mathrm{a}}$ Male $=1$, female $=2$

${ }^{*} p<.05{ }^{* * *} p<.001$ 


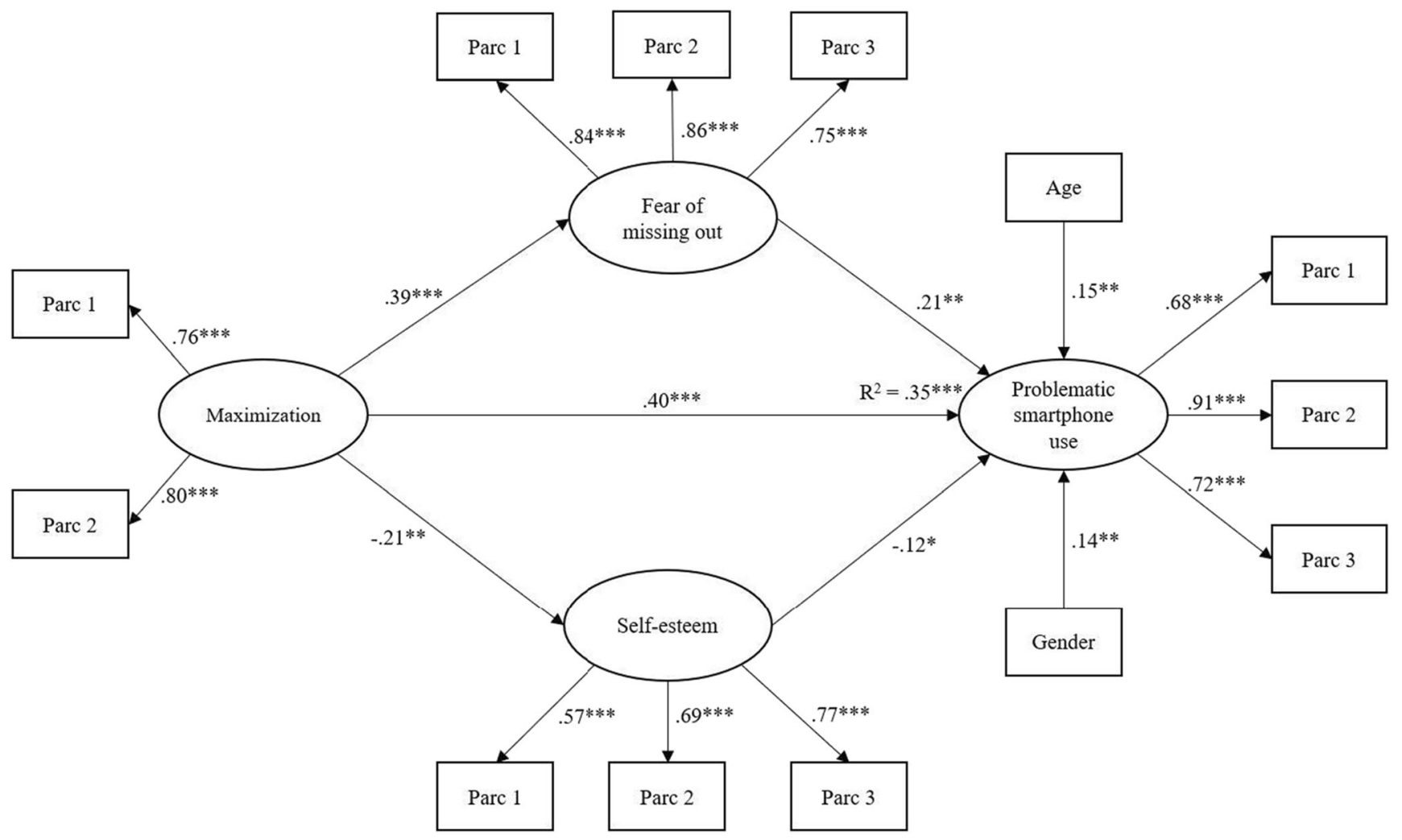

Fig. 1 Results of the structural equation model, including factor loadings and direct effects and significance levels. Note. ${ }^{*} p<.05 .{ }^{* *} p<.01 .{ }^{* * *} p<.001$

A direct, positive, and significant association between maximization and PSU was found, supporting H1. The empirical results of this study confirm that maximization inclinations are associated with PSU. These results fit with the theoretical conceptualization of the I-PACE model (Brand et al., 2019), whose focus is to explain how specific Internet-use disorders, such as PSU, are developed and maintained. Individuals with the tendency to maximize in finding the "better" option increase their risk of developing PSU. Given that impulsiveness is a personality characteristic of maximizers,

Table 2 Mediation and indirect effects with standardized estimate of fear of missing out, and self-esteem for the relationship between maximization and problematic smartphone use

\begin{tabular}{lllll}
\hline Pathway & Estimate & SE & $z$ & $p$ \\
\hline MAX -->PSU & & & & \\
Total & .512 & .059 & 8.681 & .000 \\
Direct effect & .404 & .070 & 5.745 & .000 \\
MAX --> RSE -->PSU & & & & \\
Specific indirect effect & .030 & .014 & 1.856 & .053 \\
MAX --> FoMO -->PSU & & & & \\
Specific indirect effect & .082 & .032 & 2.575 & .010 \\
\hline
\end{tabular}

Note. $\mathrm{SE}=$ standard error. $\mathrm{MAX}=$ Maximization; $\mathrm{PSU}=$ Problematic Smartphone Use; RSE = Rosenberg Self-Esteem. FoMO = Fear of Missing Out we can interpret this result in the context of studies demonstrating that impulsivity increases the risk of PSU (Kim et al., 2016; Servidio, 2019), as well as in the framework of the IPACE model, which associates impulsivity with unspecified Internet-use disorder (Brand et al., 2019). The results of the SEM indicate that the association between maximization and PSU was partially mediated by FoMO and self-esteem, revealing the predictive role of maximization in the development of PSU. Thus, this study provides new insights for future investigations aimed at identifying and reducing the risk of problematic smartphone use.

Consistent with a previous study (Müller et al., 2020), the assumption that an association could exist between maximization and FoMO (H2) was supported by the present results. This association might indicate that the tendency to maximize decisions increases the likelihood of FoMO, which then intensifies dysfunctional online interaction and specifically the risk of PSU. This positive association underlines the idea that by having several options on hand, people could change decisions and use their smartphone to search for better alternatives, and in turn increase the risk of developing PSU. People who experience FoMO tend to frequently check their social media smartphone applications, which could result in PSU (Casale et al., 2018). Similarly, because a smartphone allows access to different kind of applications, FoMO could be accentuated when the person considers multiple socially relevant events (Milyavskaya et al., 2018). According to the I-PACE model, 
people could also use their smartphone applications to cope with negative emotions arising from the feeling caused by FoMO and this mechanism characterises the development of addictive behaviour (Brand et al., 2019). In this view, PSU could be interpreted as a cognitive-emotional regulation strategy aimed at handling the stress associated with failing to fulfil personal needs. Taken together, the study's findings provide a new perspective in exploring the cause of FoMO and how it is related to PSU.

The hypothesized mediating role of FoMO (H3) in the prediction of PSU was partially supported by the results of the SEM. While this study offered empirical support for the hypothesized mediating link, the result of the partial mediation provides a clue that other mediators may have been overlooked in the proposed model. Further studies should consider examining the effect of social comparison (Festinger, 1954), which often leads people to think that they are worse off than others in certain aspects, thus increasing the experience of negative feelings. Indeed, maximizers tend to adopt strategies of seeking out and comparing alternatives because they experience a tendency towards perfectionism and this could lead to increased use of the Internet and its related technologies such as the smartphone in searching for better alternatives.

This study also confirmed that maximization was negatively related to self-esteem, which in turn was negatively related to PSU, supporting H4, that is, self-esteem partially mediates the association between maximization and PSU (H5). Moreover, the indirect effects were marginally significant. By contrast, an increase in maximization is associated with lower levels of self-esteem and life-satisfaction (Schwartz et al., 2002) and reduced self-esteem increases the risk of PSU. Maximizing is linked to social comparison which leads to more counterfactual thinking and regret and subsequently leads to greater dissatisfaction and lower personal well-being (Newman et al., 2018). As suggested by Billieux et al. (2015), individuals with low self-esteem have distorted cognitions and difficulty in emotion regulation. Thus, these people feel the need to use a smartphone to obtain comfort in affective relationships. Self-esteem is a key component of any selfimprovement program that could help people to resist addictive behaviours such as PSU. The results of the current study are consistent with previous findings which suggest that individuals with low self-esteem have the propensity of becoming Internet addicts (Andreassen et al., 2017; Servidio et al., 2018). In addition, this result is consistent with another study showing that individuals with low self-esteem have difficulty undertaking social interactions and receive less social support, and consequently feel unpleasant emotions such as loneliness (Yuchang et al., 2017). According to the I-PACE model, loneliness and self-esteem are two important factors in addictive behaviour (Brand et al., 2019), thus self-esteem could work as a protective factor against PSU. Therefore, removing irrational beliefs and improving self-esteem could reduce PSU tendencies.

\section{Limitations and Future Research}

This study has some limitations. First, due to the crosssectional nature of the study design, we cannot make any causal inferences about the observed findings. For example, the causality between maximization and PSU remains unclear. It could be plausible that smartphone use may increase the desire to search for the best alternative. According to Milyavskaya et al. (2018), for instance, we can assume circular or bi-directional association in a manner that maximization, as well as FoMO and self-esteem, affect PSU but that smartphone overuse, in turn, can influence these variables, increasing the problematic or addictive behaviour in terms of stabilizing and intensifying mechanisms (cf., Brand et al., 2019; Müller et al., 2020). Because of the cross-sectional nature of this study, future research could perhaps explore these findings using a longitudinal design.

Second, the scale for measuring maximization has not yet been validated. Based on the results of the present study, future investigations could use the proposed instrument to validate and test its psychometric properties. A third limitation was related to the sample, which was skewed towards women, who usually use the smartphone and social media applications more than men (Chen et al., 2017). Finally, the present study used only self-report questionnaires that have well-known limitations such as desirability biases.

\section{Conclusions and Practical Implications}

The results of the current study suggest that maximization tendency is a significant predictor of PSU, especially if reinforced by a belief of missing out on an opportunity for a rewarding social experience, as indicated by the partially mediating role of FoMO and self-esteem. The present study contributes to prior literature on the relationship between personality traits constructs, in this case, maximization, and PSU by considering the mediating role of FoMO and self-esteem. Furthermore, this is the first study that, to our knowledge, explores the link between maximization and PSU, indicating that maximization can be a potential PSU-driving variable. These findings have specific social and behavioural implications on the relevance that FoMO and maximization have in relation to the dysfunctional use of smartphones.

From a practical point of view, the current outcomes suggest that health professionals who are trying to reduce the prevalence of PSU should focus on increasing self-esteem and decreasing FoMO to prevent the problematic behaviour connected with the overuse of smartphone applications and related Internet technologies. Finally, the study provided 
empirical support for the I-PACE model that the interaction of several risk factors may lead to different kinds of problematic online behaviour.

Data Availability Statement The dataset generated and analysed during the current study is available from the corresponding author on reasonable request.

Funding Open Access funding provided by Università della Calabria. This research received no specific grant from any funding agency in the public, commercial, or not-for-profit sectors.

\section{Declarations}

Conflict of Interest The Author declares that they have no conflicts of interest.

Ethical Approval All procedures performed in studies involving human participants were in accordance with the ethical standards of the institutional and/or national research committee and with the 1964 Helsinki declaration and its later amendments or comparable ethical standards.

Informed Consent Informed consent was obtained from all individual participants included in the study.

Open Access This article is licensed under a Creative Commons Attribution 4.0 International License, which permits use, sharing, adaptation, distribution and reproduction in any medium or format, as long as you give appropriate credit to the original author(s) and the source, provide a link to the Creative Commons licence, and indicate if changes were made. The images or other third party material in this article are included in the article's Creative Commons licence, unless indicated otherwise in a credit line to the material. If material is not included in the article's Creative Commons licence and your intended use is not permitted by statutory regulation or exceeds the permitted use, you will need to obtain permission directly from the copyright holder. To view a copy of this licence, visit http://creativecommons.org/licenses/by/4.0/.

\section{References}

Alt, D., \& Boniel-Nissim, M. (2018). Links between adolescents' deep and surface learning approaches, problematic internet use, and fear of missing out (FoMO). Internet Interventions, 13, 30-39. https:// doi.org/10.1016/j.invent.2018.05.002.

Andreassen, C. S., Pallesen, S., \& Griffiths, M. D. (2017). The relationship between addictive use of social media, narcissism, and selfesteem: Findings from a large national survey. Addictive Behaviors, 64, 287-293. https://doi.org/10.1016/j.addbeh.2016.03. 006.

Billieux, J., Maurage, P., Lopez-Fernandez, O., Kuss, D. J., \& Griffiths, M. D. (2015). Can disordered Mobile phone use be considered a behavioral addiction? An update on current evidence and a comprehensive model for future research. Current Addiction Reports, 2, 156-162. https://doi.org/10.1007/s40429-015-0054-y.

Brand, M., Young, K. S., Laier, C., Wölfling, K., \& Potenza, M. N. (2016). Integrating psychological and neurobiological considerations regarding the development and maintenance of specific internet-use disorders: An interaction of person-affect-cognitionexecution (I-PACE) model. Neuroscience \& Biobehavioral
Reviews, 71, 252-266. https://doi.org/10.1016/j.neubiorev.2016. 08.033 .

Brand, M., Wegmann, E., Stark, R., Müller, A., Wölfling, K., Robbins, T. W., \& Potenza, M. N. (2019). The interaction of person-affectcognition-execution (I-PACE) model for addictive behaviors: Update, generalization to addictive behaviors beyond internet-use disorders, and specification of the process character of addictive behaviors. Neuroscience \& Biobehavioral Reviews, 104, 1-10. https://doi.org/10.1016/j.neubiorev.2019.06.032.

Casale, S., \& Fioravanti, G. (2020). Factor structure and psychometric properties of the Italian version of the fear of missing out scale in emerging adults and adolescents. Addictive Behaviors, 102, 106179. https://doi.org/10.1016/j.addbeh.2019.106179.

Casale, S., Rugai, L., \& Fioravanti, G. (2018). Exploring the role of positive metacognitions in explaining the association between the fear of missing out and social media addiction. Addictive Behaviors, 85, 83-87. https://doi.org/10.1016/j.addbeh.2018.05.020.

Cheek, N. N., \& Schwartz, B. (2016). On the meaning and measurement of maximization. Judgment and Decision Making, 11(2), 126-146.

Chen, F. F. (2007). Sensitivity of goodness of fit indexes to lack of measurement invariance. Structural Equation Modeling: A Multidisciplinary Journal, 14(3), 464-504. https://doi.org/10.1080/ 10705510701301834.

Chen, C., Zhang, K. Z. K., Gong, X., Zhao, S. J., Lee, M. K. O., \& Liang, L. (2017). Examining the effects of motives and gender differences on smartphone addiction. Computers in Human Behavior, 75, 891902. https://doi.org/10.1016/j.chb.2017.07.002.

Chen, I.-H., Strong, C., Lin, Y.-C., Tsai, M.-C., Leung, H., Lin, C.-Y., Pakpour, A. H., \& Griffiths, M. D. (2020). Time invariance of three ultra-brief internet-related instruments: Smartphone applicationbased addiction scale (SABAS), Bergen social media addiction scale (BSMAS), and the nine-item internet gaming disorder scale- short form (IGDS-SF9) (study part B). Addictive Behaviors, 101, 105960. https://doi.org/10.1016/j.addbeh.2019.04.018.

Choi, S.-W., Mok, J. Y., Kim, D.-J., Choi, J.-S., Lee, J.-W., Ahn, H.-J., Choi, E. J., \& Song, W.-Y. (2014). Latent class analysis on internet and smartphone addiction in college students. Neuropsychiatric Disease and Treatment, 817. https://doi.org/10.2147/NDT.S59293.

Coyne, S. M., Stockdale, L., \& Summers, K. (2019). Problematic cell phone use, depression, anxiety, and self-regulation: Evidence from a three year longitudinal study from adolescence to emerging adulthood. Computers in Human Behavior, 96, 78-84. https://doi.org/10. 1016/j.chb.2019.02.014.

De Pasquale, C., Sciacca, F., \& Hichy, Z. (2017). Italian validation of smartphone addiction scale short version for adolescents and Young adults (SAS-SV). Psychology, 08(10), 1513-1518. https://doi.org/ 10.4236/psych.2017.810100.

Duke, É., \& Montag, C. (2017). Smartphone addiction, daily interruptions and self-reported productivity. Addictive Behaviors Reports, 6 , 90-95. https://doi.org/10.1016/j.abrep.2017.07.002.

Elhai, J. D., Dvorak, R. D., Levine, J. C., \& Hall, B. J. (2017). Problematic smartphone use: A conceptual overview and systematic review of relations with anxiety and depression psychopathology. Journal of Affective Disorders, 207, 251-259. https://doi.org/10. 1016/j.jad.2016.08.030.

Elhai, J. D., Levine, J. C., Alghraibeh, A. M., Alafnan, A. A., Aldraiweesh, A. A., \& Hall, B. J. (2018). Fear of missing out: Testing relationships with negative affectivity, online social engagement, and problematic smartphone use. Computers in Human Behavior, 89, 289-298. https://doi.org/10.1016/j.chb.2018.08.020.

Elhai, J. D., Levine, J. C., \& Hall, B. J. (2019). The relationship between anxiety symptom severity and problematic smartphone use: A review of the literature and conceptual frameworks. Journal of Anxiety Disorders, 62, 45-52. https://doi.org/10.1016/j.janxdis.2018.11. 005. 
Festinger, L. (1954). A theory of social comparison processes. Human Relations, 7, 117-140.https://doi.org/10.1177/ 001872675400700202.

Hu, L., \& Bentler, P. M. (1999). Cutoff criteria for fit indexes in covariance structure analysis: Conventional criteria versus new alternatives. Structural Equation Modeling: A Multidisciplinary Journal, 6, 1-55. https://doi.org/10.1080/10705519909540118.

Huang, W.-H., \& Zeelenberg, M. (2012). Investor regret: The role of expectation in comparing what is to what might have been. Judgment and Decision making, 7(4), 441-451.

International Test Commission. (2017). The ITC Guidelines for Translating and Adapting Tests (Second edition). Retrieved from https://www.intestcom.org/files/guideline_test_adaptation_2ed.pdf

Kara, M., Baytemir, K., \& Inceman-Kara, F. (2019). Duration of daily smartphone usage as an antecedent of nomophobia: Exploring multiple mediation of loneliness and anxiety. Behaviour \& Information Technology, 1-14. https://doi.org/10.1080/0144929X.2019. 1673485.

Kim, Y., Jeong, J.-E., Cho, H., Jung, D.-J., Kwak, M., Rho, M. J., Yu, H., Kim, D. J., \& Choi, I. Y. (2016). Personality factors predicting smartphone addiction predisposition: Behavioral inhibition and activation systems, impulsivity, and self-control. PLoS One, 11, e0159788. https://doi.org/10.1371/journal.pone.0159788.

Kline, R. B. (2016). Principles and practice of structural equation modeling (Fourth edition). New York: The Guilford Press.

Kuss, D. J., Kanjo, E., Crook-Rumsey, M., Kibowski, F., Wang, G. Y., \& Sumich, A. (2018). Problematic Mobile phone use and addiction across generations: The roles of psychopathological symptoms and smartphone use. Journal of Technology in Behavioral Science, 3, 141-149. https://doi.org/10.1007/s41347-017-0041-3.

Kwon, M., Kim, D.-J., Cho, H., \& Yang, S. (2013). The smartphone addiction scale: Development and validation of a short version for adolescents. PLoS One, 8, e83558. https://doi.org/10.1371/journal. pone. 0083558 .

Lannoy, S., Chatard, A., Selimbegovic, L., Tello, N., Van der Linden, M., Heeren, A., \& Billieux, J. (2020). Too good to be cautious: High implicit self-esteem predicts self-reported dangerous mobile phone use. Computers in Human Behavior, 103, 208-213. https://doi.org/ 10.1016/j.chb.2019.09.018.

Little, T. D., Cunningham, W. A., Shahar, G., \& Widaman, K. F. (2002). To parcel or not to parcel: Exploring the question, weighing the merits. Structural Equation Modeling: A Multidisciplinary Journal, 9, 151-173. https://doi.org/10.1207/ S15328007SEM0902 1.

Little, T. D., Rhemtulla, M., Gibson, K., \& Schoemann, A. M. (2013). Why the items versus parcels controversy needn't be one. Psychological Methods, 18, 285-300. https://doi.org/10.1037/ a0033266.

Lo Coco, G., Salerno, L., Franchina, V., La Tona, A., Di Blasi, M., \& Giordano, C. (2020). Examining bi-directionality between Fear of Missing Out and problematic smartphone use. A two-wave panel study among adolescents. Addictive Behaviors, 106, 106360. https:// doi.org/10.1016/j.addbeh.2020.106360.

Long, J., Wang, P., Liu, S., \& Lei, L. (2019). Materialism and adolescent problematic smartphone use: The mediating role of fear of missing out and the moderating role of narcissism. Current Psychology. https://doi.org/10.1007/s12144-019-00526-0.

Marino, C., Gini, G., Vieno, A., \& Spada, M. M. (2018). A comprehensive meta-analysis on problematic Facebook use. Computers in Human Behavior, 83, 262-277. https://doi.org/10.1016/j.chb.2018. 02.009 .

Maydeu-Olivares, A. (2017). Maximum likelihood estimation of structural equation models for continuous data: Standard errors and goodness of fit. Structural Equation Modeling: A Multidisciplinary Journal, 24, 383-394. https://doi.org/10.1080/10705511.2016. 1269606.
Milyavskaya, M., Saffran, M., Hope, N., \& Koestner, R. (2018). Fear of missing out: Prevalence, dynamics, and consequences of experiencing FOMO. Motivation and Emotion., 42, 725-737. https://doi.org/ 10.1007/s11031-018-9683-5.

Misuraca, R., \& Fasolo, B. (2018). Maximizing versus satisficing in the digital age: Disjoint scales and the case for "construct consensus". Personality and Individual Differences, 121, 152-160. https://doi. org/10.1016/j.paid.2017.09.031.

Montag, C., Wegmann, E., Sariyska, R., Demetrovics, Z., \& Brand, M. (2019). How to overcome taxonomical problems in the study of internet use disorders and what to do with "smartphone addiction"? Journal of Behavioral Addictions, 1-7. https://doi.org/10.1556/ 2006.8.2019.59.

Müller, S. M., Wegmann, E., Stolze, D., \& Brand, M. (2020). Maximizing social outcomes? Social zapping and fear of missing out mediate the effects of maximization and procrastination on problematic social networks use. Computers in Human Behavior, 107, 106296. https://doi.org/10.1016/j.chb.2020.106296.

Muthén, L. K., \& Muthén, B. O. (2014). Mplus (version 7.2) [computer software]. Los Angeles: Muthén \& Muthén.

Newman, D. B., Schug, J., Yuki, M., Yamada, J., \& Nezlek, J. B. (2018). The negative consequences of maximizing in friendship selection. Journal of Personality and Social Psychology, 114, 804-824. https://doi.org/10.1037/pspp0000141.

Oberst, U., Wegmann, E., Stodt, B., Brand, M., \& Chamarro, A. (2017). Negative consequences from heavy social networking in adolescents: The mediating role of fear of missing out. Journal of Adolescence, 55, 51-60. https://doi.org/10.1016/j.adolescence. 2016.12.008.

Parker, A. M., de Bruin, W. B., \& Fischhoff, B. (2007). Maximizers versus satisficers: Decision-making styles, competence, and outcomes. Judgment and Decision making, 2, 342-350.

Pereira, F. S., Bevilacqua, G. G., Coimbra, D. R., \& Andrade, A. (2020). Impact of problematic smartphone use on mental health of adolescent students: Association with mood, symptoms of depression, and physical activity. Cyberpsychology, Behavior and Social Networking, 23, 619-626. https://doi.org/10.1089/cyber.2019.0257.

Polman, E. (2010). Why are maximizers less happy than satisficers? Because they maximize positive and negative outcomes. Journal of Behavioral Decision Making, 23, 179-190. https://doi.org/10. 1002/bdm.647.

Prezza, M., Trombaccia, F. R., \& Armento, L. (1997). La scala dell'autostima di Rosenberg: Traduzione e validazione Italiana. [The Rosenberg Self-Esteem Scale: Italian translation and validation.]. Bollettino Di Psicologia Applicata, 223, 35-44.

Przybylski, A. K., Murayama, K., DeHaan, C. R., \& Gladwell, V. (2013). Motivational, emotional, and behavioral correlates of fear of missing out. Computers in Human Behavior, 29(4), 1841-1848. https://doi. org/10.1016/j.chb.2013.02.014.

Purvis, A., Howell, R. T., \& Iyer, R. (2011). Exploring the role of personality in the relationship between maximization and well-being. Personality and Individual Differences, 50, 370-375. https://doi. org/10.1016/j.paid.2010.10.023.

Riordan, B, C., Flett, J, A, M., Cody, L, M., Conner, T, S., \& Scarf, D. (2019). The fear of missing out (FoMO) and event-specific drinking: The relationship between FoMO and alcohol use, harm, and breath alcohol concentration during orientation week. Current Psychology. https://doi.org/10.1007/s12144-019-00318-6.

Rosenberg, M. (1965). Society and the adolescent self-image. Princeton, NJ: Princeton University Press.

Rozgonjuk, D., \& Elhai, J, D. (2019). Emotion regulation in relation to smartphone use: Process smartphone use mediates the association between expressive suppression and problematic smartphone use. Current Psychology. https://doi.org/10.1007/s12144-019-00271-4.

Rozgonjuk, D., Sindermann, C., Elhai, J. D., \& Montag, C. (2020). Fear of missing out (FoMO) and social media's impact on daily-life and 
productivity at work: Do WhatsApp, Facebook, Instagram, and Snapchat use disorders mediate that association? Addictive Behaviors, 110, 106487. https://doi.org/10.1016/j.addbeh.2020. 106487.

Schwartz, B., Ward, A., Monterosso, J., Lyubomirsky, S., White, K., \& Lehman, D. R. (2002). Maximizing versus satisficing: Happiness is a matter of choice. Journal of Personality and Social Psychology, 83, 1178-1197. https://doi.org/10.1037/0022-3514.83.5.1178.

Servidio, R. (2019). Self-control and problematic smartphone use among Italian University students: The mediating role of the fear of missing out and of smartphone use patterns. Current Psychology. https://doi. org/10.1007/s12144-019-00373-Z.

Servidio, R., Gentile, A., \& Boca, S. (2018). The mediational role of coping strategies in the relationship between self-esteem and risk of internet addiction. Europe's Journal of Psychology, 14, 176187. https://doi.org/10.5964/ejop.v14i1.1449.

Sha, P., Sariyska, R., Riedl, R., Lachmann, B., \& Montag, C. (2019). Linking internet communication and smartphone use disorder by taking a closer look at the Facebook and WhatsApp applications. Addictive Behaviors Reports, 9, 100148. https://doi.org/10.1016/j. abrep.2018.100148.

Tabachnick, B. G., \& Fidell, L. S. (2014). Using multivariate statistics (Pearson new international edition, sixth edition). Harlow: Pearson.

Wang, P., Zhao, M., Wang, X., Xie, X., Wang, Y., \& Lei, L. (2017). Peer relationship and adolescent smartphone addiction: The mediating role of self-esteem and the moderating role of the need to belong. Journal of Behavioral Addictions, 6, 708-717. https://doi.org/10. 1556/2006.6.2017.079.

Wang, J., Wang, P., Yang, X., Zhang, G., Wang, X., Zhao, F., ... Lei, L. (2019a). Fear of missing out and procrastination as mediators between sensation seeking and adolescent smartphone addiction. International Journal of Mental Health and Addiction, 17, 1049 1062. https://doi.org/10.1007/s11469-019-00106-0.

Wang, P., Wang, X., Nie, J., Zeng, P., Liu, K., Wang, J., ... Lei, L. (2019b). Envy and problematic smartphone use: The mediating role of FOMO and the moderating role of student-student relationship. Personality and Individual Differences, 146, 136-142. https://doi. org/10.1016/j.paid.2019.04.013.

Wegmann, E., \& Brand, M. (2016). Internet-communication disorder: It's a matter of social aspects, coping, and internet-use expectancies. Frontiers in Psychology, 7. https://doi.org/10.3389/fpsyg.2016. 01747.

Wegmann, E., Oberst, U., Stodt, B., \& Brand, M. (2017). Online-specific fear of missing out and internet-use expectancies contribute to symptoms of internet-communication disorder. Addictive Behaviors Reports, 5, 33-42. https://doi.org/10.1016/j.abrep.2017.04.001.

Yuchang, J., Cuicui, S., Junxiu, A., \& Junyi, L. (2017). Attachment styles and smartphone addiction in Chinese college students: The mediating roles of dysfunctional attitudes and self-esteem. International Journal of Mental Health and Addiction, 15, 1122-1134. https:// doi.org/10.1007/s11469-017-9772-9.

Zhang, M. X., \& Wu, A. M. S. (2020). Effects of smartphone addiction on sleep quality among Chinese university students: The mediating role of self-regulation and bedtime procrastination. Addictive Behaviors, 111, 106552. https://doi.org/10.1016/j.addbeh.2020. 106552.

Publisher's Note Springer Nature remains neutral with regard to jurisdictional claims in published maps and institutional affiliations. 